\title{
PCR Detection of Four Virulence-Associated Genes of Campylobacter jejuni Isolates from Thai Broilers and Their Abilities of Adhesion to and Invasion of INT-407 Cells
}

\author{
Niwat CHANSIRIPORNCHAI ${ }^{1) *}$ and Jiroj SASIPREEYAJAN ${ }^{1)}$ \\ ${ }^{1)}$ Department of Veterinary Medicine, Faculty of Veterinary Sciences, Chulalongkorn University, Bangkok 10330, Thailand
}

(Received 11 March 2008/Accepted 16 February 2009)

\begin{abstract}
Campylobacter jejuni is a major cause of food borne pathogens in humans and a major reservoir for this pathogen is poultry. The $C$. jejuni in broilers was investigated from in the caeca of broilers. Twenty broiler/flock samples from 7 flocks were assessed. The average prevalence of $C$. jejuni was $65 \%$ in the broiler flocks. The adhesion and invasion ability of 48 strains of $C$. jejuni on INT 407 were studied. The adhesion and invasion ability of 48 Campylobacter isolates from caecal contents were analyzed with Human embryonic intestine (INT-407) cells being used as a gentamicin resistance assay. The caecal isolates exhibited a wide range of adherence and invasion ability. There was a significant correlation $(p<0.01)$ between the adherence and the invasion ability of the Campylobacter isolates. Each of the virulence-associated genes: dnaJ, $c a d F$, pldA and ciaB was detected by polymerase chain reaction from 100, 76, 31 and $41 \%$ of the Campylobacter strains, respectively. All of four virulence-associated genes were detected in 11 isolates. However, there was unclear association between the invasion ability and the presence of virulence-associated genes in this experiment, suggesting that more genes may be involved in the invasion process.
\end{abstract}

KEY WORDS: adhesion, broilers, Campylobacter jejuni, invasion, virulence gene.

J. Vet. Med. Sci. 71(6): 839-844, 2009

Campylobacter is one of most leading causes of acute bacterial diarrhoea worldwide [29]. Infection with C. jejuni or $C$. coli is characterized by the sudden onset of fever, abdominal cramps and diarrhoea with blood and leukocytes $[7,8]$. There are many possible sources of infection from $C$. jejuni and $C$. coli, as they are part of the normal intestinal flora in a wide range of birds and mammals and are transferred to other chickens during growth and processing [1, 36]. Large-scale outbreaks of human campylobacteriosis are rare and are usually linked to the consumption of polluted water or raw milk. Sporadic cases of campylobacteriosis are more common and are associated with the consumption of undercooked chicken. In the United States, case-control studies have attributed $48-70 \%$ of sporadic infections to the consumption of Campylobacter-contaminated chickens $[11,15]$. The percentage of Campylobactercontaminated chicken carcasses varies, often between 50 and $90 \%$, depending on the time of year and the number of carcasses tested. One study has found that as many as $98 \%$ of chicken carcasses may be contaminated with C. jejuni by the time of sale [38]. Campylobacter organisms cause disease via at least three mechanisms: (i) intestinal colonization by ingested organisms and the production of bacterial cytotoxin $[10,14,17]$, inducing diarrhoea, (ii) bacterial invasion of intestinal cells [35], resulting in damage to the mucosal surface cells of the jejunum, ileum and colon, and (iii) extra intestinal translocation $[13,19]$, in which the organisms cross the intestinal epithelium and migrate via the lymphatic system to various extra intestinal sites [42]. The adherence to and invasion of $C$. jejuni into host cells has been studied

\footnotetext{
* Correspondence to: Chansiripornchai, N., Department of Veterinary Medicine, Faculty of Veterinary Sciences, Chulalongkorn University, Bangkok 10330, Thailand.

e-mail: cniwat@chula.ac.th
}

in a variety of cell lines $[11,16,19,26]$. Human embryonic intestine (INT-407) cells have been widely used to assess the ability of enteric bacteria to adhere to and invade the epithelium. The ability of $C$. jejuni to adhere to and invade the epithelial cells of the gastrointestinal tract is important to the development of Campylobacter-mediated enteritidis [27, 39]. Despite the recognition of $C$. jejuni invasion of the intestinal epithelium as a possible pathogenic mechanism, studies defining the precise mechanism of $C$. jejuni entry and the identification and characterization of entry-promoting proteins are in their infancy. The molecular basis of the pathogenicity of Campylobacter has not been clearly understood. Some genes are involved in Campylobacter adhesion and invasion. Four mutant strains derived from F38011, an excellent colonizer of chicken caeca, dnaJ, cadF, pldA and $c i a B$ are incapable of colonizing the ceca [20, 23, 43, 44]. cadF (Campylobacter adhesin to fibronectin) is an outer membrane protein, which encodes a protein that interacts with a host extracellular matrix protein fibronectin [31], and is required for Campylobacter adherence to and colonization of the host cell surface [20]. Other genes such as ciaB (Campylobacter invasive antigen B) [21, 34] and pldA encoded outer membrane phospholipase A [34] are involved in host cell invasion and are important for caecal colonization $[21,43]$. The $c i a B$, pldA and $d n a J$ (heat shock protein) genes are important to caecal colonization and mutations of these genes severely limit the ability of the mutant strains to colonize the chicken caeca $[20,43,44]$. The objective of this study was to study the prevalence of $C$. jejuni in Thai broiler caeca and their ability to adhere and invade and the presence of the 4 genes that are involved in the adherence and invasion of the Campylobacter in the INT-407 cell culture model.

Bacterial strains and culture conditions: The caecal con- 
tents of 7 broiler flocks were collected using a sterile swab from 20 samples from each flock that were located in Lopburi province, a dense area of broiler integrated farming in the central plains of Thailand. Samples were collected and sent to the laboratory within $3 \mathrm{hr}$ and processed between June and October 2006. The chicken farms in this study were industrialized facilities and parts of an integrated production system. Strict biosecurity measures were applied in these flocks. Antimicrobials used on these farms were regulated by the companies purchasing these animals for slaughter. At least one week before sampling, broilers had not been treated with antimicrobial agents prior to sample collection. Campylobacter isolation and identification has previously been described by membrane filtration technique [24]. Briefly, the swabs were incubated in Preston broth (Nutrient broth no.2) (Oxoid, Hampshire, England) containing 5\% lysed horse blood, Campylobacter growth supplement and modified Preston selective supplement (2500 IU of polymyxin $\mathrm{B}$, and $5 \mathrm{mg}$ each of rifampicin, trimethoprim and amphotericin B) (Oxoid, Hampshire, England) for $24 \mathrm{hr}$ or overnight at $37^{\circ} \mathrm{C}$. Eight drops of each broth culture were spotted on a cellulose acetate membrane with $0.45 \mu \mathrm{m}$ pores of diameter $47 \mathrm{~mm}$ (Sartorius, Goettingen, Germany). The membrane was placed on the surface of a blood agar base no. 2 (Oxoid, Hampshire, England) containing 5\% whole sheep blood and Campylobacter growth supplement (Oxoid, Hampshire, England). The membrane was left on the agar surface for $30 \mathrm{~min}$ to let all the fluid pass through. The pores allowed relatively slender and naturally spiralling 'cork screw' motiles to pass through whereas other bacteria harboured in the intestine were excluded by the $0.45 \mu \mathrm{m}$ cellulose membrane. The culture plates were incubated for 48 hr at $37^{\circ} \mathrm{C}$ in an atmosphere of $5 \% \mathrm{O}_{2}, 10 \% \mathrm{CO}_{2}$ and $85 \% \mathrm{~N}_{2}$ using an anaerobic jar with CampyGen (Oxoid, Hampshire, England). Colonies of Campylobacter were identified to the genus level by typical morphology on a Gram stain (slender, curved, 'seagull wing' shaped or spiral, Gram negative rods). Species differentiation was performed on the basis of nalidixic acid sensitivity and hippurate hydrolysis [28, 37] and PCR analysis [40]. A well-characterized human clinical strain, C. jejuni 81116 (kindly provided by Prof. Dr. J.P.M. van Putten, Utrecht University, The Netherlands) which has been described as a good colonizer of the chicken intestinal tract $[2,9]$ was used. Non-invasive Escherichia coli laboratory strain, DH5 $\alpha$, was used as positive and negative controls for all the analyses. The $C$. jejuni strains were suspended in Brain Heart Infusion containing $15 \%$ glycerol and stored at $-80^{\circ} \mathrm{C}$ until use.

Cell cultures: The human embryonic intestine (INT-407) cells (ATCC CCL-6), kindly provided by Prof. Dr. J.P.M. van Putten, Utrecht University, The Netherlands, were maintained in DMEM (Gibco, Auckland, New Zealand) with a 5\% FBS (foetal bovine serum), penicillin and streptomycin (Gibco, Auckland, New Zealand) in a $5 \% \mathrm{CO}_{2}$ humidified incubator. Confluent stock cultures were trypsinized and new stock cultures were seeded with $10^{5}$ cells/ml on to 24-well tissue culture plates (Corning,
U.S.A.) for the adherence and invasion assay and incubated at $37^{\circ} \mathrm{C}$ in a humidified $5 \% \mathrm{CO}_{2}$ incubator for $48 \mathrm{hr}$, and a semi-confluent monolayer was obtained. Prior to the experiment, the monolayer was washed and incubated with DMEM without antibiotic and FBS.

Adherence and invasion assay: The adhesion and invasion assays were performed by the method of Konkel et al. [22] with some modifications. Briefly, C. jejuni strains were grown microaerobically on Blood agar No. 2 with supplement for $48 \mathrm{hr}$ at $37^{\circ} \mathrm{C}$. Bacteria were harvested from the plates with PBS (phosphate buffered saline) and adjusted spectrophotometrically to approximately $1 \times 10^{7}$ bacteria/ $\mathrm{m} l$. The containing CFU (colony forming unit) of approximately 100 times higher than the cell number, was inoculated into duplicated wells of a 24 -well tissue culture plate containing semiconfluent monolayers of INT-407 cells. The infected monolayers were incubated for $3 \mathrm{hr}$ at $37^{\circ} \mathrm{C}$ in a $5 \% \mathrm{CO}_{2}$ humidified atmosphere to allow for bacterial adherence and internalization. For determination of adherence, the cells were washed 3 times with PBS and the cell monolayer was lysed with $0.5 \%$ deoxycholate $(\mathrm{W} / \mathrm{V})$ (Sigma-Aldrich, Auckland, New Zealand) and the total bacteria associated with the cells (intracellular and extracellular bacteria) were enumerated by plating serial dilutions of the lysates on Blood agar No. 2 with 5\% sheep blood and counting the resultant colonies. In order to measure bacterial invasion, the infected cells were washed 2 times with PBS and incubated in fresh PBS containing $1 \%$ foetal bovine serum (FBS) and $150 \mu \mathrm{g} / \mathrm{ml}$ gentamicin for $2 \mathrm{hr}$ to kill the remaining viable extracellular bacteria. In preliminary experiments $150 \mu \mathrm{g} / \mathrm{m} l$ of gentamicin killed all bacterial strains $3 \mathrm{hr}$ after exposure. Quantification of viable intracellular bacteria was performed by washing the infected eukaryotic cells twice with PBS and subsequently lysing with $0.5 \%$ deoxycholate $(\mathrm{W} / \mathrm{V})$. Following serial dilution in PBS, the released intracellular bacteria were enumerated as described for the adherence assay. The correlation between the adherence to and invasion of the INT-407 cells by Campylobacter isolates was analyzed by linear regression using SPSS (SPSS Inc., Chicago, Ill.).

Detection of virulence-associated genes: PCR (polymerase chain reaction) was used to detect the 4 Campylobacter genes that are associated with invasion in the genomic DNA of Campylobacter isolates: $c a d F, c i a B$, pldA and dnaJ. PCR primers specific for these genes were designed based on the gene sequence information in the GenBank database and in previous published studies (Table 1). Conserved sequences of each gene were selected and a set of primers was used for each gene. Template DNAs for PCR were extracted by the boiling method described previously [30]. Fresh cultures of Campylobacter isolates were suspended in $1 \mathrm{ml}$ of PBS and boiled at $95^{\circ} \mathrm{C}$ for $10 \mathrm{~min}$. After centrifugation at $14,000 \times \mathrm{g}$ for $2 \mathrm{~min}$, the supernatants were collected and stored at $-20^{\circ} \mathrm{C}$ until use. PCRs were carried out using GoTaq Green MasterMix (Promega, U.S.A.) with 30 cycles of amplification in thermocycler (Biometra, Goettingen, Germany). The cycling program 
Table 1. Campylobacter virulence genes and primer sequences used for PCR identification

\begin{tabular}{|c|c|c|c|c|c|}
\hline Target gene & Primers & Sequence (5' to $\left.3^{\prime}\right)$ & Annealing temperature $\left({ }^{\circ} \mathrm{C}\right)$ & PCR Product (bp) & References \\
\hline \multirow[t]{2}{*}{$c a d F$} & $c a d F-F 2 B$ & TTGAAGGTAATTTAGATATG & \multirow[t]{2}{*}{42} & \multirow[t]{2}{*}{400} & \multirow[t]{2}{*}{21} \\
\hline & $c a d F-\mathrm{R} 1 \mathrm{~B}$ & CTAATACCTAAAGTTGAAAC & & & \\
\hline \multirow[t]{2}{*}{$\operatorname{ciaB}$} & $\operatorname{ciaB}-652$ & TGCGAGATTTTTCGAGAATG & \multirow[t]{2}{*}{58} & \multirow[t]{2}{*}{527} & \multirow[t]{2}{*}{42} \\
\hline & $c i a B-1159$ & TGCCCGCCTTAGAACTTACA & & & \\
\hline \multirow[t]{2}{*}{ C. jejuni pldA } & pldA-361 & AAGAGTGAGGCGAAATTCCA & \multirow[t]{2}{*}{58} & \multirow[t]{2}{*}{385} & \multirow[t]{2}{*}{42} \\
\hline & pldA-726 & GCAAGATGGCAGGATTATCA & & & \\
\hline \multirow[t]{2}{*}{ dnaJ } & dnaJ-F301 & ATTGATTTTGCTGCGGGTAG & \multirow[t]{2}{*}{42} & \multirow[t]{2}{*}{177} & \multirow[t]{2}{*}{ This study } \\
\hline & dnaJ-R477 & ATCCGCAAAAGCTTCAAAAA & & & \\
\hline
\end{tabular}

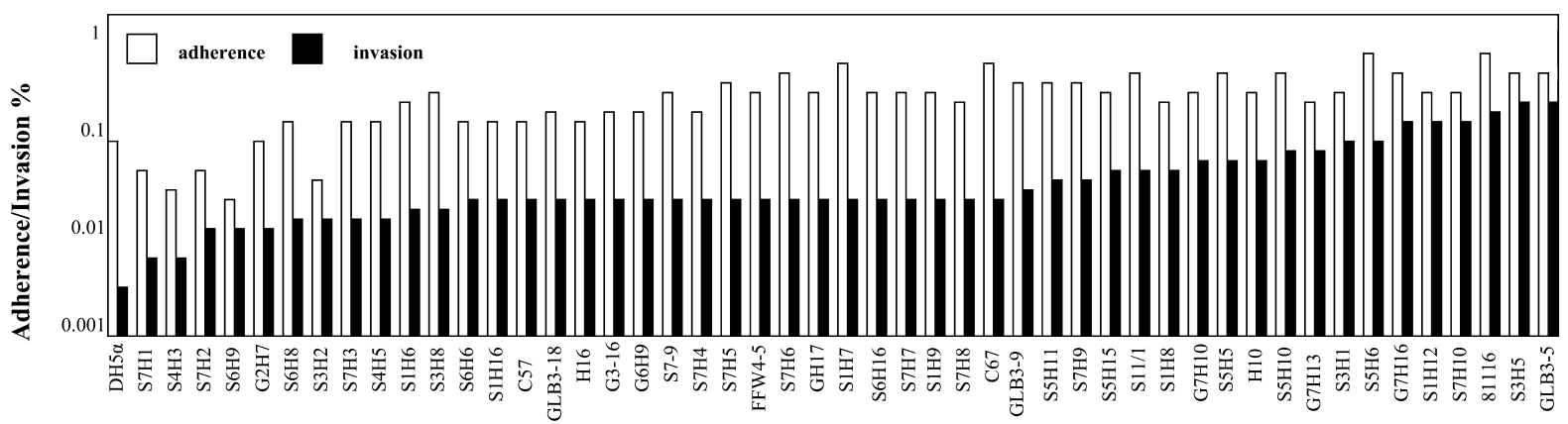

Fig. 1. The ability of Campylobacter jejuni isolates to adhere to and to invade INT 407 human intestinal epithelial cells.

was denaturation at $94^{\circ} \mathrm{C}$ for $1 \mathrm{~min}$, annealing at a temperature specific to each primer pair for $45 \mathrm{~s}$, and extension at $72^{\circ} \mathrm{C}$ for $45 \mathrm{~s}$. In negative control reactions, the DNA template or the primer were replaced by sterile deionized water. PCR products were separated on $2 \%$ agarose gels and bands were stained with ethidium bromide and visualized using a gel document system (Vilber Lourmat, France).

Prevalence of $C$. jejuni in broilers: The $C$. jejuni in broilers was investigated from the caeca of broilers. Twenty broilers per flock from 7 flocks were assessed. The prevalence of $C$. jejuni in each flock was as follows $80 \%, 70 \%$, $55 \%, 75 \%, 55 \%, 65 \%$ and $55 \%$. The average prevalence of C. jejuni was $65 \%$ in the broiler flocks.

Adhesion and invasion by C. jejuni: To test the pathogenic properties of Campylobacter isolates, the adhesion and invasion abilities of 49 Campylobacter isolates were analyzed with Human embryonic intestine (INT-407) cells using a gentamicin resistance assay. After $3 \mathrm{hr}$ incubation, the 49 Campylobacter isolates adhered to INT-407 cells between $1.51 \times 10^{4}$ and $3.65 \times 10^{5}$ from the isolates of $\mathrm{S} 6 \mathrm{H} 9$ and 81116 , respectively, and that could be expressed as 0.03 to $0.73 \%$ adherence of the starting viable inoculum. The invasion abilities of the 49 isolates to INT-407 were between $3.5 \times 10^{3}$ and $1.41 \times 10^{5}$ from the isolates of S7H1 and GLB3 -5 , respectively, and that can be expressed as 0.007 to $0.28 \%$ of the starting viable inoculum. The average percentages of $49 C$. jejuni for adherence to and invasion were $0.36 \pm 1.9$ and $0.05 \pm 0.05$, respectively (Fig. 1). There was a significant correlation $(p<0.01)$ between the adherence ability and the invasion ability of the Campylobacter isolates.
Presence of the putative virulence-associated genes: Although the genes that determine the infectivity of Campylobacter have not been thoroughly studied, several genes are thought to be involved in Campylobacter adherence to and invasion of host cells. Forty-six percent of Campylobacter isolates examined in this study possessed two of the 4 virulence-associated genes. The percentages of dnaJ, cadF, pldA and ciaB genes of 49 isolates were 100, 76, 31 and $41 \%$, respectively (Table 2 ). All 4 virulence genes were detected in the positive control strain and the other 11 isolates dnaJ gene was detected in all Campylobacter jejuni strains, in contradiction to $p l d A$ which was detected from 15 isolates.

Campylobacter is one of the major foodborne pathogens and is widespread in poultry meat and poultry products. Although the samples were collected from a strict biosecure farm, a high prevalence of $C$. jejuni was found. The average prevalence of $C$. jejuni isolated from the broiler caeca was $65 \%$ which is similar to a previous report that the prevalence of Campylobacter spp. in Thai broilers was 64\% [32]. However, little is known about the pathogenicity of food-contaminating strains and the molecular basis of Campylobacter pathogenicity. In this study, we examined the ability of Campylobacter jejuni strains isolated from the caecal contents of broilers to adhere to and invade the cells of the INT-407 human intestinal cell line and determined the association with the presence of certain virulence genes which affect on poultry colonization $[43,44]$ and the adherence and invasion abilities of Campylobacter jejuni isolates. The adherence and invasion abilities of the caecal isolates varied considerably, from invasive levels similar to that of 
Table 2. Detection of different putative virulence and in 48 C. jejuni isolates obtained from Thai broilers

\begin{tabular}{|c|c|c|c|c|c|c|c|c|c|}
\hline strains & $c a d F$ & pldA & $c i a B$ & $d n a J$ & strains & $c a d F$ & pldA & $c i a B$ & $d n a J$ \\
\hline DH5 $\alpha$ & - & - & - & - & S1H7 & - & - & - & + \\
\hline S7H1 & + & - & - & + & S6H16 & + & - & - & + \\
\hline S4H3 & - & - & + & + & S7H7 & + & + & + & + \\
\hline $\mathrm{S} 7 \mathrm{H} 2$ & - & - & + & + & S1H9 & - & - & - & + \\
\hline S6H9 & + & - & - & + & S7H8 & + & - & + & + \\
\hline G2H7 & + & - & - & + & C67 & + & + & - & + \\
\hline S6H8 & + & - & - & + & GLB3-9 & + & - & - & + \\
\hline $\mathrm{S} 3 \mathrm{H} 2$ & - & - & - & + & S5H11 & - & - & - & + \\
\hline S7H3 & + & + & + & + & S7H9 & + & + & + & + \\
\hline S4H5 & - & - & - & + & S5H15 & + & - & - & + \\
\hline S1H6 & + & - & + & + & $\mathrm{S} 11 / 1$ & + & + & + & + \\
\hline S3H8 & + & - & - & + & S1H8 & + & + & + & + \\
\hline S6H6 & - & - & - & + & G7H10 & + & - & - & + \\
\hline S1H16 & + & + & - & + & S5H5 & + & - & + & + \\
\hline C57 & + & + & + & + & H10 & - & - & - & + \\
\hline GLB3-18 & + & - & - & + & S5H10 & + & - & - & + \\
\hline H16 & + & - & - & + & G7H13 & + & - & - & + \\
\hline G3-16 & + & - & - & + & S3H1 & + & + & + & + \\
\hline G6H9 & - & - & - & + & S5H6 & + & + & - & + \\
\hline S7-9 & + & - & - & + & G7H16 & + & - & + & + \\
\hline S7H4 & - & - & + & + & S1H12 & + & + & + & + \\
\hline S7H5 & - & - & + & + & S7H10 & + & + & + & + \\
\hline FFW4-5 & + & - & - & + & 81116 & + & + & + & + \\
\hline S7H6 & + & - & - & + & S3H5 & + & + & + & + \\
\hline GH17 & + & - & - & + & GLB3-5 & + & + & + & + \\
\hline
\end{tabular}

C. jejuni 81116 to 40 -fold lower than that of $C$. jejuni 81116 , indicating that not all Campylobacter strains that contaminate broiler caeca are able effectively to invade human intestinal epithelial cells. Moreover, 2 of 49 tested isolates had invasion abilities higher than that of $C$. jejuni 81116. Because animal models that completely mimic Campylobacter infection in humans are not available, the cell culture model using human intestinal epithelial cells is a useful tool for evaluating the abilities of Campylobacter food isolates to adhere to and invade the human intestinal epithelium. The INT-407 cell line has been widely used for studies of the pathogenicity of many human enteric pathogens, such as Salmonella Enteritidis, Campylobacter jejuni, and enteropathogenic E. coli $[6,25,33]$. Even though the process of Campylobacter adhering to and invading INT407 human intestinal epithelial cells in culture does not exactly mimic the process in vivo, the cell culture model allowed us to determine the relative adherence and invasion abilities of the caeca isolates in comparison to well-studied human clinical strain C. jejuni 81116 . From our study, a multiplicity of about 100 infections was used and the invasion and adherence levels of the human clinical strain $C$. jejuni 81116 reported here are slightly lower than a previous report by Biswas et al. [6] that $0.7416-2.1714 \%$ and $0.0012-0.4226 \%$ of the range of adherence and invasion, respectively. Colonization or adherence of microbial pathogens to mucosal surfaces is the primary step of infection and appears to be a prerequisite for invasion in most cases $[3,18$, 41]. In this study, we analyzed the relationship between adherence and invasion efficiency in Campylobacter caecal isolates using statistical tests. There was a significant correlation $(p<0.01)$ between the adherence and the invasion ability of the Campylobacter isolates according to Zheng et al. [42]. Thus, the adherence of Campylobacter may facilitate invasion into host cells. Bacterial virulence is multifactorial and is affected by the expression of virulence genes. To determine the relationship between the presence of virulence genes in $C$. jejuni caeca isolates and the ability of these isolates to adhere to and invade human intestinal epithelial cells, the prevalence of the putative virulence genes dnaJ, $c a d F, c i a B$ and pldA among the 49 Campylobacter isolates was determined by PCR. Using PCR primers that targeted to conserved sequences for each gene, we detected all putative virulence genes in 12 of the 49 Campylobacter isolates including the positive control strain. The gene dnaJ was detected in all strains of Campylobacter caecal isolates. Only $76 \%$ of $c a d F$ genes were detected in all 49 chicken isolates which is contrary to the $100 \%$ detection of $c a d F$ genes from the isolates of Danish turkeys $[4,5]$. This result may be caused by geographic and species differences. The previous studies revealed that $d n a J, c a d F$, pldA and $c i a B$ genes are important to host cell invasion and caecal colonization [20, 31, 34, 43, 44]. However, we could not find a clear association between the invasion ability and the presence of virulence-associated genes in this experiment, suggesting that more genes may be involved in the invasion process. Furthermore, it can't be ruled out that the nucleotide sequences selected for PCR detection of these genes aren't conserved in the isolates studied herein. To confirm this point, therefore, southern blot analysis is necessary. 
ACKNOWLEDGEMENTS. Our work was supported by The Thailand Research Fund 2005-2007, MRG 4880182. We would like to thank Prof. Dr. J.P.M van Putten, Utrecht University, The Netherlands, for materials and technical support, and Dr. P. Pathanasophon, National Institute of Animal Health, Thailand, for valuable help in technical advice.

\section{REFERENCES}

1. Achen, M., Morishita, T.Y. and Ley, E.C. 1998. Shedding and colonization of Campylobacter jejuni in broilers from day-ofhatch to slaughter age. Avian Dis. 42: 732-737.

2. Ahmed, I.H., Manning, G., Wassenaar, T.M., Cawthraw, S. and Newell, D.G. 2002. Identification of genetic differences between two Campylobacter jejuni strains with different colonization potentials. Microbiology 148: 1203-1212.

3. Allos, B.M. and Blaser, M.J. 1995. Campylobacter jejuni and the expanding spectrum of related infections. Clin. Infect. Dis. 20: 1092-1099.

4. Bang, D.D., Borck, B., Nielsen, E.M., Scheutz, F., Pedersen, K. and Madsen, M. 2004. Detection of seven virulence and toxin genes of Campylobacter jejuni isolates from Danish turkeys by PCR and cytolethal distending toxin production of the isolates. J. Food Prot. 67: 2171-2177.

5. Bang, D.D., Nielsen, E.M., Scheutz, F., Pedersen, K., Handberg, K. and Madsen, M. 2003. PCR detection of seven virulence and toxin genes of Campylobacter jejuni and Campylobacter coli isolates from Danish pigs and cattle and cytolethal distending toxin production of the isolates. J. Appl. Microbiol. 94: 1003-1014.

6. Biswas, D., Itoh, K. and Sasakawa, C. 2000. Uptake pathways of clinical and healthy animal isolates of Campylobacter jejuni into INT-407 cells. FEMS Immunol. Med. Microbiol. 29: 203211.

7. Blaser, M.J., Berkowitz, I.D., LaForce, F.M., Cravens, J., Reller, L.B. and Wang, W.L. 1979. Experimental Campylobacter enteritis: clinical and epidemiological features. Annu. Intern. Med. 91: 179-185.

8. Blaser, M.J., Wells, J.G., Feldman, R.A., Pollard, R.A. and Allen, J.R. 1983. Campylobacter enteritis in the United States. A multicenter study. Annu. Intern. Med. 98: 360-365.

9. Cawthraw S.A., Wassenaar, T.M., Ayling, R. and Newell, D.G. 1996. Increased colonization potential of Campylobacter jejuni strain 81116 after passage through chickens and its implication on the rate of transmission within flocks. Epidemiol. Infect. 117: 213-215.

10. Cover, T.L., Perez-Perez, G.I. and Blaser, M.J. 1990. Evaluation of cytotoxic activity in fecal filtrates from patients with Campylobacter jejuni or Campylobacter coli enteritis. FEMS Microbiol. Lett. 58: 301-304.

11. de Melo, M.A. and Pechere, J.C. 1988. Effect of mucin on Campylobacter jejuni association and invasion on HEp-2 cells. Microb. Pathog. 5: 71-76.

12. Deming, M.S., Tauxe, R.V., Blake, P.A., Dixon, S.E., Fowler, B.S., Jones, T.S. Lockamy, E.A., Patton, C.M. and Sikes, R.O. 1987. Campylobacter enteritis at a university: transmission from eating chicken and from cats. Am. J. Epidemiol. 126: 526-534.

13. Grant, C.C., Konkel, M.E., Cieplak, W. Jr. and Tompkins, L.S. 1993. Role of flagella in adherence, internalization, and translocation of Campylobacter jejuni in nonpolarized and polarized epithelial cell cultures. Infect. Immun. 61: 1764-1771.

14. Griffiths, P.L. and Park, R.W. 1990. Campylobacters associated with human diarrhoeal disease. J. Appl. Bacteriol. 69: 281-301.

15. Harris, N.V., Weiss, N.S. and Nolan, C.M. 1986. The role of poultry and meats in the etiology of Campylobacter jejuni/coli enteritis. Am. J. Public Health 76: 407-411.

16. Hu, L. and Kopecko, D.J. 1999. Campylobacter jejuni 81-176 associates with microtubules and dynein during invasion of human intestinal cells. Infect. Immun. 67: 4171-4182.

17. Johnson, W.M. and Lior, H. 1984. Toxins produced by Campylobacter jejuni and Campylobacter coli. Lancet 28: 229-230.

18. Ketley, J.M. 1997. Pathogenesis of enteric infection by Campylobacter. Microbiology 143: 5-21.

19. Konkel, M.E., Corwin, M.D., Joens, L.A. and Cieplak, W. 1992. Factors that influence the interaction of Campylobacter jejuni with cultured mammalian cells. J. Med. Microbiol. 37: 30-37.

20. Konkel, M.E., Garvis, S.G., Tipton, S.L., Anderson, D.E. Jr. and Cieplak, W. Jr. 1997. Identification and molecular cloning of a gene encoding a fibronectin-binding protein (CadF) from Campylobacter jejuni. Mol. Microbiol. 24: 953-963.

21. Konkel, M.E., Gray, S.A., Kim, B.J., Garvis, S.G. and Yoon, J. 1999. Identification of the enteropathogens Campylobacter jejuni and Campylobacter coli based on the cadF virulence gene and its product. J. Clin. Microbiol. 37: 510-517.

22. Konkel, M.E. and Joens, L.A. 1989. Adhesion to and invasion of HEp-2 cells by Campylobacter spp. Infect. Immun. 57: 2984-2990.

23. Konkel, M.E., Kim, B.J., Klena, J.D., Young, C.R. and Ziprin R. 1998. Characterization of the thermal stress response of Campylobacter jejuni. Infect. Immun. 66: 3666-3672.

24. Kulkarni, S.P., Lever, S., Logan, J.M.J., Lawson, A.J., Stanley, J. and Shafi, M.S. 2003. Detection of Campylobacter species: a comparison of culture and polymerase chain reaction based methods. J. Clin. Pathol. 55: 749-753.

25. Kumar, S.S., Malladi, V., Sankaran, K., Haigh, R., Williams, P. and Balakrishnan, A. 2001. Extrusion of actin-positive strands from Hep-2 and Int 407 cells caused by outer membrane preparations of enteropathogenic Escherichia coil and specific attachment of wild type bacteria to the strands. Can. J. Microbiol. 47: 727-734.

26. Lara-Tejero, M. and Galan, J.E. 2001. CdtA, CdtB, and CdtC form a tripartite complex that is required for cytolethal distending toxin activity. Infect. Immun. 69: 4358-4365.

27. Lee, C.A. and Falkow, S. 1990. The ability of Salmonella to enter mammalian cells is affected by bacterial growth state. Proc. Natl. Acad. Sci. U.S.A. 87: 4304-4308.

28. Lior, H. 1984. New, extended biotyping scheme for Campylobacter jejuni, Campylobacter coli, and Campylobacter laridis. J. Clin. Microbiol. 20: 636-640.

29. Mead, P.S., Slutsker, L., Dietz, V., McCaig, L.F., Bresee, J.S., Shapiro, C., Griffin, P.M. and Tauxe, R.V. 1999. Food-related illness and death in the United States. Emerg. Infect. Dis. 5: 607-625.

30. Millar, B.C., Jiru, X., Moore, J.E. and Earle, J.A. 2000. A simple and sensitive method to extracted bacterial, yeast and fungal DNA from blood culture material. J. Microbiol. Methods 42: 139-147.

31. Monteville, M.R., Yoon, J.E. and Konkel, M.E. 2003. Maximal adherence and invasion of INT 407 cells by Campylobacter jejuni requires the CadF outer-membrane protein and microfilament reorganization. Microbiology 149: 153-165. 
32. Padungtod, P. and Kaneene, J.B. 2005. Campylobacter in Food Animals and Humans in Northern Thailand. J. Food Prot. 68: 2519-2526.

33. Pang, J.C., Lin, J.S., Tsai, C.C. and Tsen, H.Y. 2006. The presence of major world-wide clones for phage type 4 and 8 Salmonella enterica serovar Enteritidis and the evaluation of their virulence levels by invasiveness assays in vitro and in vivo. FEMS Microbiol. Lett. 263: 148-154.

34. Rivera-Amill, V., Kim, B.J., Seshu, J. and Konkel, M.E. 2001. Secretion of the virulence-associated Campylobacter invasion antigens from Campylobacter jejuni requires a stimulatory signal. J. Infect. Dis. 183: 1607-1616.

35. Ruiz-Palacios, G.M., Escamilla, E. and Torres, N. 1981. Experimental Campylobacter diarrhea in chickens. Infect. Immun. 34: 250-255.

36. Shanker, S., Lee, A. and Sorrell, T.C. 1990. Horizontal transmission of Campylobacter jejuni amongst broiler chicks: experimental studies. Epidemiol. Infect. 104: 101-110.

37. Smibert, R.M. 1984. Genus Campylobacter Sebald and Veron 1963, 907 AL . pp. 111-118. In: Bergey's Manual of Systematic Bacteriology, vol. 1 (Krieg, N.R. ed.), Williams and Wilkins, Baltimore, Md.

38. Stern, N.J. and Pretanik, S. 2006. Counts of Campylobacter spp. on U.S. broiler carcasses. J. Food Prot. 69: 1034-1039.
39. van Spreeuwel, J.P., Duursma, G.C., Meijer, C.J., Bax, R., Rosekrans, P.C. and Lindeman, J. 1985. Campylobacter colitis: histological immunohistochemical and ultrastructural findings. Gut 26: 945-951.

40. Wang, G., Clark, C.G., Taylor, T.M., Pucknell, C., Barton, C., Price, L., Woodward, D.L. and Rodgers, F.G. 2002. Colony multiplex PCR assay for identification and differentiation of Campylobacter jejuni, C. coli, C. lari, C. upsaliensis, and C. fetus subsp. fetus. J. Clin. Microbiol. 40: 4744-4747.

41. Wooldridge, K.G. and Ketley, J.M. 1997. Campylobacter-host cell interactions. Trends Microbiol. 5: 96-102.

42. Zheng, J., Meng, J., Zhao, S., Singh, R. and Song, W. 2006. Adherence to and Invasion of Human Intestinal Epithelial Cells by Campylobacter jejuni and Campylobacter coli Isolates from Retail Meat Products. J. Food Prot. 69: 768-774.

43. Ziprin, R.L., Young, C.R., Byrd, J.A., Stanker, L.H., Hume, M.E., Gray, S.A., Kim, B.J. and Konkel, M.E. 2001. Role of Campylobacter jejuni potential virulence genes in cecal colonization. Avian Dis. 45: 549-557.

44. Ziprin, R.L., Young, C.R., Stanker, L.H., Hume, M.E. and Konkel, M.E. 1999. The absence of cecal colonization of chicks by a mutant of Campylobacter jejuni not expressing bacterial fibronectin-binding protein. Avian Dis. 43: 586-589. 